\title{
MULTICENTER STUDY OF STENTLESS VALVE REPLACEMENT IN THE SMALL AORTIC ROOT
}

Ulrik Hvass, MD

George M. Palatianos, $\mathrm{MD}^{\mathrm{b}}$

Romeo Frassani, $\mathrm{MD}^{\mathrm{c}}$

Cesare Puricelli, $\mathrm{MD}^{\mathrm{c}}$

Mark O’Brien, $\mathrm{MD}^{\mathrm{d}}$
Objective: A clinical study was conducted to evaluate the results of stentless porcine valves in patients with a small aortic root (19- and 21-mm aortic anulus). Methods: Of 567 patients, from 4 surgical institutions, 171 patients $(30.1 \%)$ had a small aortic root, comprising 163 cases with calcified aortic stenosis and 8 cases with predominant valvular insufficiency. Sixty patients had associated mitral or coronary lesions. Mean age was $72 \pm 4.2$ years. Forty-seven patients with a small aortic root had a 19-mm anulus, and 124 patients had a 21-mm anulus. The body surface area was, respectively, $1.55 \pm 0.2 \mathrm{~m}^{2}$ and $1.78 \pm 0.45 \mathrm{~m}^{2}$. Hemodynamic evaluation of the stentless valve comprised serial measures of mean gradients, effective orifice area, and left ventricular mass reduction. Complication rates for secondary events were evaluated over a 6-year period. Results: The hospital mortality rate was $3.5 \%$. The mean gradients after the first year were $9 \pm 2 \mathrm{~mm} \mathrm{Hg}$ and $6 \pm 1.7 \mathrm{~mm} \mathrm{Hg}$ in patients with a 19-mm and a $21-\mathrm{mm}$ anulus, respectively. Effective orifice area was $1.45 \pm 0.3 \mathrm{~cm}^{2}$ and $1.72 \pm 0.4 \mathrm{~cm}^{2}$. Gradients and surfaces remained stable throughout the study period. Aortic regurgitation was zero to trace. Left ventricular mass at discharge and at 1 year were, respectively, $296 \pm 127 \mathrm{~g}$ and $215 \pm 102 \mathrm{~g}$ for patients with a 19-mm anulus and 281 $\pm 75 \mathrm{~g}$ and $236 \pm 15 \mathrm{~g}$ for patients with a 21-mm anulus. Conclusions: Stentless valves are a suitable device for elderly patients with small aortic roots, which leave only mild residual obstruction. (J Thorac Cardiovasc Surg 1999;117:267-72)
0 btaining optimal hemodynamics after aortic valve replacement (AVR) may be a more pertinent goal than previously considered. It is possible that low gradients, correlating with completeness of regression of left ventricular (LV) hypertrophy and better recovery of LV function, could enhance event-free patient outcome. ${ }^{1}$ Although no data yet establish firmly that mismatch reduces long-term survival, such intuitive expectancy is leading surgeons to be concerned that an adequate-sized replacement device be used and that even elderly patients should benefit from optimal hemo-

From the Hopital Bichat, Paris, France, ${ }^{a}$ Onassis Center, Athens, Greece, ${ }^{\mathrm{b}}$ Ospedale S. Maria Della Misericordia, Udine, Italy, ${ }^{\mathrm{c}}$ and Prince Charles Hospital, Brisbane, Queensland, Australia. ${ }^{\mathrm{d}}$

Read at the Seventy-eighth Annual Meeting of The American Association for Thoracic Surgery, Boston, Mass, May 3-6, 1998.

Received for publication May 8, 1998; revisions requested June 16, 1998; revisions received Sept 17, 1998; accepted for publication Sept 18, 1998.

Address for reprints: Ulrik Hvass, MD, Hopital Bichat, 46 rue Henri Huchard, Paris 75018, France.

Copyright (C) 1999 by Mosby, Inc.

$0022-5223 / 99 \$ 8.00+0 \quad \mathbf{1 2 / 6 / 9 4 6 4 1}$ dynamics such as encountered in young patients after AVR with homografts or autografts. ${ }^{2,3}$

Mechanical valves and, to a greater degree, stentmounted biologic valves expose patients to a higher risk of residual gradients, especially patients with a small aortic root and a body surface area (BSA) exceeding $1.70 \mathrm{~m}^{2}$, or when expected orifice area index is below $0.80 \mathrm{~cm}^{2} / \mathrm{m}^{2}$. This quantitative frame allows us to define replacement device mismatch, ${ }^{4}$ although its anticipated significance may vary with age groups and be of greater significance in young and active patients.

Compared with stent mounted valves, stentless biologic valves offer superior hemodynamic profiles. ${ }^{5-9}$ The improved effective orifice areas and lower residual gradients were expected to reduce incidence, if not completely rule out mismatch. This multicenter study evaluated the aptitude of the CryoLife-O'Brien (CryoLife International, Marietta, Ga) stentless porcine valve to achieve optimum hemodynamics in elderly patients who have a small aortic root with a measured aortic anulus of 19 or $21 \mathrm{~mm}$. Differences in valve calibration by 3 manufacturers and oversizing the selected device by the surgeon are the reasons we preferred to 


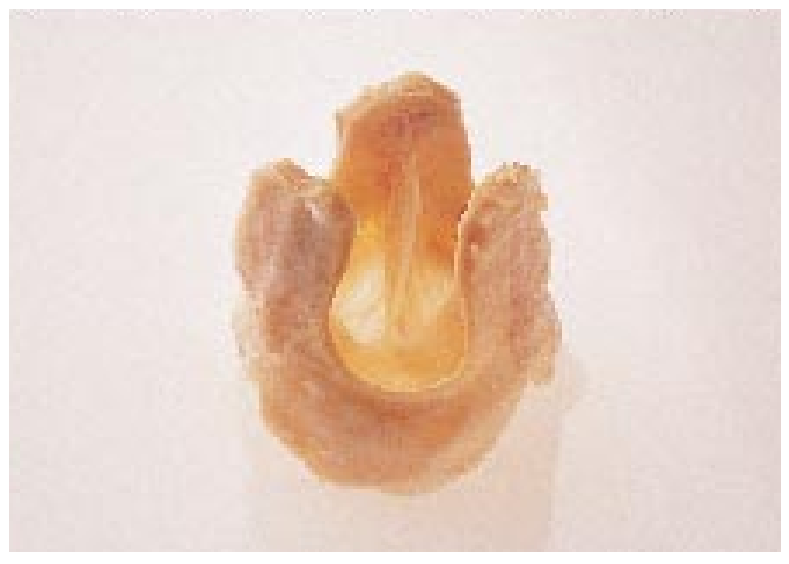

Fig 1. The CryoLife-O'Brien porcine stentless aortic valve.

define the small aortic root by the intraoperative measured size of the aortic anulus and not according to the size of the device inserted.

\section{Patients and methods}

Patient population. Between September 1991 and September 1997, 567 patients received a CryoLife-O'Brien stentless porcine aortic valve in one of the four referral hospitals. Of this group, 171 patients $(30.1 \%)$ had a small aortic root. These patients had an aortic anulus, measured in the operating room by means of a Hegar dilator, with a diameter of 19 or $21 \mathrm{~mm}$. Patient characteristics are shown in Table I. As with all series dealing with calcified aortic stenosis in elderly patients, most are women who are symptomatic and in sinus rhythm. In the group, 93.6\% of patients (44 of 47 patients) were women with a $19-\mathrm{mm}$ aortic anulus, and $64.5 \%$ of patients ( 80 of 124 patients) had a $21-\mathrm{mm}$ anulus. The prevalence of patients with a 19 - or $21-\mathrm{mm}$ aortic anulus was $8.2 \%$ (47 of 567 patients) and $21.8 \%$ (124 of 567 patients), respectively.

The study valve. The CryoLife-O'Brien stentless porcine aortic prosthesis (Fig 1) is a composite design, constructed with noncoronary leaflets obtained from 3 porcine valves. Leaflets are carefully excised from valves already fixed in glutaraldehyde under low or near zero pressure. Individual noncoronary leaflets are matched for size and symmetry to assure synchronous opening and to promote maximum leaflet coaptation. The matched set of leaflets is sutured together along the free edges of the porcine aortic wall at the leaflet commissures. The base of the valve is finished with a blanket stitch to assure its integrity. No Dacron reinforcement is necessary, which is a significant difference when compared with other stentless valves.

\section{Surgical technique}

Valve size selection. After removing the native valve, we feel that it is important to debride all the calcium on the anulus and, at times, necessary to peel off calcifications from the Valsalva sinus and the sinotubular junction, which results in a
Table I. Patient characteristics

\begin{tabular}{|c|c|}
\hline No. of patients & $171 / 567(30.1 \%)$ \\
\hline \multicolumn{2}{|l|}{ Age $(y)$} \\
\hline Mean \pm SD & $72 \pm 4.2$ \\
\hline Range & $59-90$ \\
\hline \multicolumn{2}{|l|}{ Sex } \\
\hline Male & $41 / 171(24 \%)$ \\
\hline Female & $130 / 171(76 \%)$ \\
\hline \multicolumn{2}{|l|}{ Size of the aortic anulus } \\
\hline $19 \mathrm{~mm}$ & 47/171 (27.5\%) \\
\hline $21 \mathrm{~mm}$ & $124 / 171(72.5 \%)$ \\
\hline \multicolumn{2}{|l|}{$\operatorname{BSA}\left(m^{2}\right)$} \\
\hline 19-mm anulus & $1.55 \pm 0.2$ \\
\hline 21-mm anulus & $1.78 \pm 0.45$ \\
\hline \multicolumn{2}{|l|}{ Aortic valve lesion } \\
\hline Stenosis & $163(95.4 \%)$ \\
\hline Insufficiency & $8(4.6 \%)$ \\
\hline \multicolumn{2}{|l|}{ ECG } \\
\hline Sinus rhythm & $130(76 \%)$ \\
\hline Atrial fibrillation & $29(17 \%)$ \\
\hline Complete heart block & $12(7 \%)$ \\
\hline Coronary artery disease & $39(22.8 \%)$ \\
\hline Mitral valve disease & $21(12.2 \%)$ \\
\hline \multicolumn{2}{|l|}{ New York Heart Association } \\
\hline Class I-II & $28(16 \%)$ \\
\hline Class III-IV & $143(84 \%)$ \\
\hline
\end{tabular}

much more flexible aortic root. The aortic anulus is measured with a Hegar dilator. Being seated above the anulus, the selected valve must offer the same internal diameter as the measured transannular diameter. For instance, a 21-mm xenograft with an internal diameter of $19 \mathrm{~mm}$ will match a measured transannular diameter of $19 \mathrm{~mm}$, and a patient with a 21-mm aortic anulus will receive a $23-\mathrm{mm}$ graft. This does not correspond to oversizing, and the scalloped CryoLifeO'Brien valve will sit in a natural position within the Valsalva sinus. Keeping to these selection rules, the surgeon can be confident that the valve will be seated correctly in the Valsalva sinus above the anulus and that the xenograft will offer the maximum effective orifice area (EOA). The implantation technique is simple and needs only one running suture line as previously reported. ${ }^{6,7}$ None of the patients underwent a procedure of annular enlargement.

Echocardiography. All patients underwent preoperative transthoracic echocardiography. The referring cardiologist, to assess valve function, monitored all survivors with serial transthoracic echocardiograms, the first before discharge, at 6 months, and then at least annually. Transvalvular gradients and LV mass were available for all patients except for those who had not yet reached the 1-year mark. The calculation of EOA was restricted to 87 cases with adequate echographic visibility to allow for secure measures of subaortic diameter and flow calculations. Transesophageal echocardiography was not performed. At each follow-up, M-mode, 2-dimensional, and Doppler echocardiography was performed. Standard apical, parasternal, and subcostal views were obtained. The following parameters were measured: LV end- 
Table II. Hemodynamic data of CryoLife-O'Brien stentless valves in patients with an aortic anulus of 19 and $21 \mathrm{~mm}$

\begin{tabular}{lcc}
\hline & $19 \mathrm{~mm}$ & $21 \mathrm{~mm}$ \\
\hline Mean gradients (mm Hg) & & \\
Before the operation & $52.5 \pm 30.4$ & $57.5 \pm 19.8$ \\
Discharge & $12 \pm 4.8$ & $10.5 \pm 2$ \\
1 Year & $9 \pm 2$ & $6 \pm 1.7$ \\
EOA $\left(\mathrm{cm}^{2}\right)$ & & \\
$\quad$ Discharge & $1.25 \pm 0.1$ & $1.58 \pm 0.6$ \\
$\quad$ Year & $1.45 \pm 0.3$ & $1.72 \pm 0.4$ \\
Effective area index $\left(\mathrm{cm}^{2} / \mathrm{m}^{2}\right)$ & & \\
$\quad$ Discharge & $0.80 \pm 0.1$ & $0.88 \pm 0.1$ \\
1 Year & $0.93 \pm 0.1$ & $0.96 \pm 0.1$ \\
LV mass $(\mathrm{g})$ & $296 \pm 127$ & $281 \pm 75$ \\
$\quad$ Before the operation & $215 \pm 102$ & $236 \pm 15$ \\
$\quad$ Year & & \\
LV mass index $\left(\mathrm{g} / \mathrm{m}^{2}\right)$ & $190 \pm 48$ & $157 \pm 34$ \\
$\quad$ Before the operation & $138 \pm 36$ & $133 \pm 8$ \\
1 Year & & \\
\hline
\end{tabular}

systolic and end-diastolic diameters, ejection fraction and fractional shortening, interventricular septum and posterior wall thickness, and maximum and mean flow velocity across the stentless valve. The following parameters were then calculated: LV mass was calculated from M-mode measurements with the formula modified by Devereux and Reicher; maximum and mean aortic valve gradients were calculated by a modified Bernoulli equation; the EOA was calculated by the continuity equation; the values of EOA and of LV mass were indexed for BSA, the results of which were averaged.

Complication rates for primary and secondary events. Operative and long-term mortality and morbidity information was collected during the 6-year follow-up period with the guidelines of Edmund and associates ${ }^{10}$ for reporting morbidity and mortality information after cardiac valvular operations.

Statistical analysis. Discrete variables are presented as counts and percentages. Continuous variables are presented as means \pm SD. For complication rates, both the simple percentage of patients with early events ( $<30$ days) and linearized rates for late events ( $>30$ days) are reported. Linearized rates (in percentage per patient-year) were calculated by dividing the number of events by patient-years of follow-up and multiplying by $100 \%$. Survival was determined by the Kaplan-Meier product limit method. Comparison over a time period of 2 continuous variables with normal distribution (gradients EOA and LV mass) were assessed by the Student $t$ test.

\section{Results}

The 30-day mortality rate was $3.5 \%$ (6 patients: 2 , emergency redo operations; 1 , sepsis; 1 , mitral annular disruption; 1, bleeding; and 1, myocardial infarction).
Table III. Complication rate for secondary events

\begin{tabular}{lcc}
\hline Event & No. & $\begin{array}{c}\text { Linearized rate } \\
(\% / p t-y)\end{array}$ \\
\hline Structural valve deterioration & 0 & 0 \\
Nonstructural dysfunction & 0 & 0 \\
Valve thrombosis & 0 & 0 \\
Embolism & 2 & 0.4 \\
Anticoagulant-related bleeding & 0 & 0 \\
Operated valvular endocarditis & 2 & 0.4 \\
Reoperation & 2 & 0.4 \\
Nonfatal cardiac events & 2 & 0.4 \\
$\quad$ (myocardial infarction) & & \\
$\quad$ Valve-related death & 1 & 0.2 \\
Cardiac deaths & 0 & 0 \\
Total deaths & 5 & 1.2 \\
\hline
\end{tabular}

During the early years of the study, all patients were given oral anticoagulants over a 2- to 3-month period, maintained only in the presence of atrial fibrillation. Presently most patients receive only low-dose aspirin after the operation. Echographic measurements of gradients, EOA, and LV mass at discharge and after 1 year are reported in Table II. Differences in all groups are significant with $P<.001$. During the first year, improved hemodynamics can be demonstrated in most patients. Regurgitation is absent or a trace. None of the patients underwent cardiac catheterization.

At the time of this report 92 patients have reached the 2-year follow-up interval; 61 patients have reached the 3 -year mark; 42 patients, the 4-year mark; 25 patients, the 5-year mark; and 14 patients, the 6-year limit, which accounts for a cumulated follow-up of 401 patient-years. Complication rates for secondary events are listed in Table III. Follow-up was $99 \%$ complete with 2 patients lost for follow-up. Ninety-two percent of the patients are in New York Heart Association class I-II. The 6-year survival is $87 \% \pm 5 \%$.

\section{Discussion}

The increasing number of elderly patients who undergo operations for senescent calcification of the aortic valve reflects the satisfactory outlook for operative survivors with symptomatic relief and regained autonomy in most instances. ${ }^{11}$ Tissue valves are the preferred prosthesis in this population because of the shorter life expectancy and good durability of tissue prostheses in patients over 70 years of age.

A small aortic root is not an uncommon finding in elderly patients. ${ }^{12}$ In our present study group, we encountered a small aortic anulus in 30\% of the patients. In patients over 80 years of age, the percentage reaches $40 \%$. The prevalence of a $19-\mathrm{mm}$ root was 
Table IV. Hemodynamic data of 4 valves used for a 19-mm or a 21-mm aortic anulus

\begin{tabular}{lcc}
\hline Aortic anulus & $19 \mathrm{~mm}$ & $21 \mathrm{~mm}$ \\
\hline CryoLife-O’Brien* & $12 \pm 4.2$ & $9 \pm 2$ \\
Carpentier-Edwards pericardial $\dagger$ & $26.3 \pm 9.4$ & $22.6 \pm 9.7$ \\
Medtronic Hall $\$$ & $17 \pm 5$ & $8 \pm 4$ \\
St Jude Medical§ & $22 \pm 7$ & $12 \pm 5$ \\
\hline
\end{tabular}

Mean gradients, $\mathrm{mm} \mathrm{Hg} \pm \mathrm{SD}$.

*Present study.

$\dagger$ MacDonald et al: Ann Thorac Surg 1997;63:362-6. ${ }^{14}$

\$Manufacturer's data.

§Panidis et al. J Am Coll Cardiol 1986;8:317-26. ${ }^{30}$

$8 \%$ and that of a 21-mm root, $28 \%$. Patients with a small aortic root and a BSA of more than $1.70 \mathrm{~m}^{2}$ are considered to be at risk of replacement device mismatch that is responsible for suboptimal hemodynamic performance and higher residual postoperative gradients. Stented valves constructed with bovine pericardium show no significant improvement compared with porcine valves in respect to transvalvular gradients and EOA in the small sizes ${ }^{13-15}$ and therefore do not preclude the necessity of enlarging the aortic anulus in selected active elderly patients. The Manougian technique allows accommodating stented prostheses 1 or 2 sizes larger than what would have been possible without enlargement. In this respect, the Manougian technique is efficient, but a certain reluctance always remained in performing these more extensive operations in elderly patients who may also have fragile and calcified ascending aortas. ${ }^{16,17}$

What are the advantages of obtaining optimal hemodynamics after AVR? It is amply demonstrated that low gradients correlate with a more complete regression of LV hypertrophy and enhance recovery of LV systolic and diastolic function. Del Rizzo and associates ${ }^{18}$ studied serial echocardiograms and showed a statistical relationship between residual pressure gradients and LV mass. Monrad and associates ${ }^{19}$ studied LV mass index 5 to 10 years after the operation and found compelling evidence that LV hypertrophy persists because of the obstructive nature of the replacement device.

What are the long-term effects of persistent hypertrophy? Although we are lacking randomized controlled studies, there are some indications toward a deleterious effect of persistent hypertrophy that suggests that patient-device mismatch has an influence on long-term survival. He and associates ${ }^{20}$ reported on a 30 -year follow-up of 404 patients who had undergone AVR with small aortic roots and showed that mismatch is a negative determinant of long-term survival. Lund and asso- ciates $^{21}$ brought indirect evidence about the influence of residual gradients after AVR: among 176 late deaths, $23.9 \%$ were due to sudden cardiac deaths and $30 \%$ were due to congestive heart failure. Residual hypertrophy affects the systolic and diastolic ventricular function, so it appears that the size and type of the valve has an important bearing on postoperative $\mathrm{LV}$ performance. ${ }^{22-24}$ Walter and associates ${ }^{25}$ showed that, although patients have a decrease in LV mass after AVR, it was greater in those with stentless valves. The nonrandomized study of David and associates ${ }^{26}$ casematched the patients who received the Toronto SPV valve (St Jude Medical, Inc, St Paul, Minn) with those patients who received the Hancock II valve (Medtronic, Inc, Minneapolis, Minn). When the duration of followup exceeds 5 years, the actuarial survival of patients with a stentless valve is $93 \%$ versus $86 \%$. There is a strong suggestion that improved hemodynamics and LV function translates directly into better event-free survival. In contradiction, the study by Sawant and associates ${ }^{27}$ claims that using a $19-\mathrm{mm}$ St Jude Medical valve for AVR in patients with a BSA of more than 1.70 was not a determinant of long-term survival. Christakis and Goldman, ${ }^{28}$ however, considered the study to be underpowered in respect to the follow-up and number of cases, forbidding firm conclusions.

All large studies agree that stentless valves demonstrate excellent hemodynamics, superior to those encountered with stented models. This feature seemed attractive for patients with small aortic roots and was expected to allow AVR without having to enlarge the anulus.

The CryoLife-O'Brien stentless prosthesis has proved to be easy to handle in the presence of a small aortic root. The low transprosthetic gradients obtained in the study group and the effective orifice index superior to $0.8 \mathrm{~cm}^{2} / \mathrm{m}^{2}$ met with our expectations and ruled out the need to take into consideration the individual patient's BSA and the anticipated physical activity. Comparable results have been reported with other types of stentless valves; for instance, the 21-mm and the 23mm CryoLife-O'Brien stentless valve inserted in patients with a 19-mm and 21-mm aortic anulus, respectively, produces results that are very close to the reported results of 21- and 23-mm Medtronic Freestyle or Toronto SVP. Lower residual gradients and larger EOAs correlate with a substantial regression of LV hypertrophy, a major determinant of LV function and possibly of long-term clinical status.

Finally, the gradients recorded with the unstented valves selected for a 19 - or 21-mm aortic anulus are lower ${ }^{6,8,9}$ than those reported for 19- or 21-mm 
mechanical valves ${ }^{30}$ (Table IV). Therefore mechanical valves should not necessarily be considered as an alternative to annular enlargement in elderly patients with small aortic roots, and surgeons should become familiar with the unstented porcine valves.

\section{Conclusion}

The CryoLife-O'Brien stentless porcine prostheses leaves only mild residual obstruction in the subgroup of elderly patients with a small aortic root. There is presently no indication to enlarge the aortic anulus, regardless of the patient's BSA and anticipated exercise capacity. Residual gradients are consistently low, and an EOA index above $0.9 \mathrm{~cm}^{2} / \mathrm{m}^{2}$ at 1 year makes it our valve of choice for AVR in the elderly patient with a small aortic root.

\section{REFERENCES}

1. Orsinelli DA, Aurigemma GP, Battista S, Krendell S, Gaasch WH. Left ventricular hypertrophy and mortality after aortic valve replacement for aortic stenosis: a high risk subgroup identified by preoperative relative wall thickness. J Am Coll Cardiol 1993;22: 1679-83.

2. O'Brien MF, Stafford EG, Gardner MAH, et al. Allograft aortic valve replacement: long term follow-up. Ann Thorac Surg 1995; 60:S65-70

3. Jin XY, Zhang Z, Gibson DG, Yacoub MH, Pepper JR. Changes in left ventricular function and hypertrophy following aortic valve replacement using aortic homografts, stentless or stented valves. Ann Thorac Surg 1996;62:683-90.

4. Dumesnil JG, Honos GN, Lemieux M, Beauchemin J. Validation and application of indexed aortic prosthetic valve areas calculated by Doppler echocardiography. J Am Coll Cardiol 1990;16: 637-43.

5. Barratt-Boyes BG, Christie GW. What is the best bioprosthetic operation for the small aortic root? Allograft, autograft, porcine, pericardial, stented or unstented? J Card Surg 1994;9(suppl): 158-64.

6. Hvass U, Chatel D, Assayag P, et al. The O'Brien-Angell stentless porcine valve: early results with 150 implants. Ann Thorac Surg 1995;60:S414-7.

7. O'Brien MF. Composite stentless xenograft for aortic valve replacement: clinical evaluation of function. Ann Thorac Surg 1995;60:S406-9.

8. Westaby S, Amarasena N, Ormerod 0, Amarasena C, Pillai R. Aortic valve replacement with the Freestyle stentless xenograft. Ann Thorac Surg 1995;60:S422-7.

9. David TE, Feindel CM, Bos J, Sun Z, Scully HE, Rakowski H. Aortic valve replacement with a stentless porcine aortic valve: a six-year experience. J Thorac Cardiovasc Surg 1994;108:1030-6.

10. Edmunds LH, Clark RE, Cohn LH, Grunkenmeier GL, Miller DC, Weisel RD. Guidelines for reporting morbidity and mortality after cardiac valvular operations. J Thorac Cardiovasc Surg 1996;112:708-11.

11. Gehlot A, Mullany CH, Ilstrup C, et al. Aortic valve replacement in patients aged 80 years and older: early and long-term results. J Thorac Cardiovasc Surg 1996;111:1026-36.
12. Sintek CF, Fletcher AD, Khonsari S. Stentless porcine aortic root: valve of choice for the elderly patient with small aortic root? J Thorac Cardiovasc Surg 1995;109:871-6.

13. Khan SS, Mitchell RS, Derby GC, Oyer PE, Miller DC. Differences in Hancock and Carpentier-Edwards porcine xenograft aortic valve hemodynamics: effect of valve size. Circulation 1990;82(Suppl):IV117-24.

14. McDonald ML, Daly RC, Schaff HV, et al. Hemodynamic performance of small aortic valve bioprostheses: Is there a difference? Ann Thorac Surg 1997;63:362-6.

15. Pelletier LC, Carrier M, Leclerc Y, Le Page G, deGuise P, Dyrda I. Porcine versus pericardial bioprostheses: a comparison of late results in 1,593 patients. Ann Thorac Surg 1989;47:352-61.

16. Manouguian S, Seybold-Epting W. Patch enlargement of the aortic valve by extending the aortic incision into the anterior mitral leaflet. J Thorac Cardiovasc Surg 1979;78:402-8.

17. Kitamura M, Satoh M, Hachida M, et al. Aortic valve replacement in small aortic annulus with or without annular enlargement. J Heart Valve Dis 1996;5(suppl):S284-8.

18. Del Rizzo DF, Goldman BS, Christakis GT, David TE. Hemodynamic benefits of the Toronto stentless valve. J Thorac Cardiovasc Surg 1996;112:1431-45.

19. Monrad ES, Hess OM, Tomoyuki M, Corin WJ, Krayenbuehl HP. Time course of regression of left ventricular hypertrophy after aortic valve replacement. Circulation 1998;77:1345-55.

20. He GW, Grunkemeier GL, Getely HL, Furnary AP, Starr A. Up to thirty-year survival after aortic valve replacement in the small aortic root. Ann Thorac Surg 1995;59:1056-62.

21. Lund O, Pilegaard HK, Magnussen K, Knudsen MA, Nielsen TT, Albrechtsen OK. Long-term prosthesis-related and sudden cardiac-related complications after aortic valve replacement for aortic stenosis. Ann Thorac Surg 1990;50:396-406.

22. Gonzales-Juanatey JR, Garcia-Acuna JM, Fernandez MV, et al. Influence of the size of aortic valve prostheses on hemodynamics and change in left ventricular mass: implications for the surgical management of aortic stenosis. J Thorac Cardiovasc Surg 1996; 112:273-80.

23. Meloni L, Ricchi A, Cirio E, et al. Echocardiographic assessment of aortic valve replacement with stentless porcine xenografts. Am J Cardiol 1995;76:294-6.

24. Kratz JM, Sade RM, Crawford FA, Crumbley AJ III, Stroud MR. The risk of small St Jude valve prostheses. Ann Thorac Surg 1994;57:1114-9.

25. Walter T, Falk V, Autschbach R, et al. Hemodynamic assessment of the stentless Toronto SPV bioprosthesis by echocardiography. J Heart Valve Dis 1994;3:657-65.

26. David TE, Puchmann R, Ivanov J, et al. Aortic valve replacement with stentless and stented porcine valves: a case-match study. J Thorac Cardiovasc Surg 1998;116:236-41.

27. Sawant D, Singh AK, Feng WC, Bert AA, Rotenberg F. Nineteenmillimeter St Jude Medical heart valve prosthesis: up to sixteenyear follow-up. Ann Thorac Surg 1997;63:964-70.

28. Christakis GT, Goldman BS. Do small aortic valves influence long term survival? Ann Thorac Surg 1997;63:933-4.

29. Gross C, Harringer W, Mair R, et al. Aortic valve replacement: Is the stentless xenograft an alternative to the homograft? Early results of a randomized study. Ann Thorac Surg 1995;60:S418-21.

30. Panidis IP, Ross J Jr, Mintz GS. Normal and abnormal prosthetic valve function as assessed by Doppler echocardiography. J Am Coll Cardiol 1986;8:317-26. 


\section{Discussion}

Dr Edward D. Verrier (Seattle, Wash). Thank you for the opportunity to discuss this multicenter, multinational trial of the CryoLife-O'Brien stentless bioprosthesis in small aortic roots.

Stentless aortic prostheses are receiving increasing attention as a viable and potentially preferred prosthesis in the aortic position, as our understanding of the LV outflow tract, aortic valve, and aortic root physiology and pathology evolve. Insights into this pathophysiology have increased with the use of echocardiography, particularly now 3-dimensional echocardiography, computer modeling, such as finite element analysis, and extensive surgical experience.

The reported potential advantages of the stentless valve technology include lower peak and mean gradients and therefore greater EOAs, particularly in the smaller sizes, accelerated reduction of LV wall mass, and remodeling of the ventricle, thereby enhancing recovery of both systolic and diastolic function, no need of warfarin anticoagulation, and even a hint of improved long-term survival.

The reported potential disadvantages of the stentless technology include greater technical demands at the time of insertion and lack of any long-term data concerning durability.

I have a few concerns related to the study design and conclusions. The measurement of LV wall mass can be particularly difficult, variable, and operator-dependent. How did you assure consistency and quality of the echocardiographic measurements with 4 centers in 4 countries? Was consideration given to an independent observer reviewing the echocardiograms, blinded to either the size of the valve inserted or the site of implantation? I believe this would have significantly strengthened the conclusions of the trial.

In almost all other studies of stentless valves, the relative percentage of 19- and 21-mm valves is smaller than the $30 \%$ reported incidence in this series. Now, this may reflect different sizing techniques based on various valve manufacturing specifications. One other thought is that to achieve the benefits or the potential benefits of stentless technology, significantly greater annular debridement is required to maximally relieve any LV outflow tract obstruction. In addition, valve relations then become more determined by the sinus or the sinotubular junction. How much annular debridement was required in this to achieve the remodeling that is associated with this stentless-type valve?

The measurement of EOA is a calculated number based on cardiac index, even though it is widely used for valve comparisons. How was this done in your investigation? This is important because the EOAs reported in this series are considerably larger than any other series of stentless or stented bioprostheses. How is that achieved when the effective anulus is 19 or $21 \mathrm{~mm}$ if you do not do the debridement, particularly if you leave residual calcium in the anulus?

Overall, this is an excellent study for the early and late results of the stentless prosthesis; it uses a multicentered design, and it also gives significant insights into a number of the problems that we have in measurement and in comparison of these various prostheses. I believe that all of us are going to have to make sure we know the standardization of these measurements for these conclusions to extend from one series to the next.

Dr Hvass. I agree with you that the parameters that we are using to evaluate these valves are very observer-dependent and that there were differences between the 4 different teams, especially in masses and even more in EOA. I know that we have low gradients and small EOAs when compared with the series of Mark O'Brien, who has slightly higher gradients and even larger EOAs. So there is an individual variation and also differences in the teams. But, once put together, it is interesting to see that, generally speaking, we are all tending to the same excellent results.

Concerning LV masses, it is fairly obvious that we know the calculations of LV mass. There is a great variation, and there is a mean error that could go up to $30 \%$, so it is not a very precise parameter either. I think we are lacking precise parameters to evaluate these valves, that seems pretty obvious, because the exact size and the exact dimension of the subvalvular area will vary considerably with the observer.

There was a question also about debridement. I think you have to take out as much calcium as you can. You have to have a flexible anulus and a flexible aortic root. At times we have to take out layers of calcium that are in the sinuses or near the commissures.

Measuring, it has been a straightforward type of measuring. We have been using Hagar probes, which are much more sensitive and much more reliable than any other types of measurers.

Dr Stephen Westaby (Oxford, England). One thing puzzles me. In both the Freestyle and Toronto valves, the transvalvular gradients fall with time and the EOA increases. These findings are not due to changes in the valve itself but to rapidly improving LV function. Your parameters did not change, according to your abstract. Could you speculate as to the difference between the O'Brien valve and the Toronto and the Freestyle valves?

Dr Hvass. I thought there was a change. There was a change between measurements at discharge and at 1 year in gradients and EOA.

Dr Tirone E. David (Toronto, Ontario, Canada). Were the changes significant?

Dr Hvass. Yes, the changes were significant.

Dr David. So the valve did increase the orifice with time?

Dr Hvass. There was an increased orifice. I do not know where it comes from, if it comes from a better LV function or not, but there was a difference there. I think all these stentless valves behave in the same way. The techniques to insert them are a little different and one gets used to one or the other, but finally the immediate and long-term results, or at least up until now, have been exactly the same. 